Василенко В.Н. Экономическое пространство и формы пространственной организации хозяйства и населения

УДК 332.1:334.78

DOI: $10.21779 / 2500-1930-2017-32-3-55-63$

\title{
В.Н. Василенко
}

\section{Экономическое пространство и формы пространственной организации хозяйства и населения ${ }^{1}$}

Государственное учреждение «Институт экономических исследований»; ДНР, 283048, г. Донеик, ул. Университетская, 77; bulava1953@mail.ru

Решения современных проблем регионального развития очень часто сопряжены с поиском нового инструментария, способного обеспечивать адекватное восприятие и воздействие на окружающую действительность. Одним из таких инструментов выступает пространственный подход. Такой подход позволяет рассматривать любой экономический объект в его пространственно-связевом построении. Таким образом экономическое пространство предложено рассматривать через призму, во-первых, некоторых форм пространственной организации и позиционирования материальных объектов или элементов производительных сил, во-вторых, множества экономических отношений и связей. Из-за отсутствия универсального определения экономического пространства в статье логическая схема его познания рассматривается с точки зрения семантической формы (научного термина), организационно-экономического содержания (научного понятия) и экономической сущности (научной категории). На основе рассмотрения мнений некоторых российских ученых-регионалистов по поводу экономического пространства показаны отличительные особенности его формы и содержания. Архитектура (содержательная сторона) экономического пространства показана как сочетание следующих элементов: хозяйства, населения, экономических связей и территории.

Ключевые слова: пространственный подход, производительные силь, формы пространственной организации хозяйства и населения, архитектура экономического пространства.

В последние годы в научном сообществе регионалистов приобрела особую популярность тематика исследования экономических и социальных проблем в контексте формирования и структуризации экономического пространства: локального, регионального, национального или мирового, включая и широкий спектр теоретизирования об его возможных формах и содержании. Можно предположить, что актуализация пространственной проблематики стала своеобразным ответом на отсутствие даже скудных результатов использования на практике других методов и способов решения территориальных проблем, например территориального размещения производительных сил (обеспечивающих решение задач размещения производства или перспектив развития той или иной отрасли, в которой территории отводится роль «формы существования отрасли») или территориальной организации производительных сил (призванной решать задачи, сопряженные с взаимодействием отдельных элементов производительных сил, но с учетом особенностей «ландшафта» конкретной территории).

И здесь пространственный подход позволяет, с одной стороны, по-новому посмотреть на содержание происходящих процессов, а с другой, предложить весьма не-

\footnotetext{
${ }^{1}$ Статья подготовлена по материалам доклада, представленного на III Международной научнопрактической конференции «Модернизация экономических систем: опыт и перспективы», которая прошла 27-28 апреля 2017 года в Дагестанском государственном университете (г. Махачкала, РФ).
} 
Василенко В.Н. Экономическое пространство и формы пространственной организации хозяйства и населения

тривиальные способы решения текущих проблем. Причем с точки зрения не только практической пригодности пространственного подхода и соответствующего инструментария решения проблемных вопросов, но и методической обоснованности их с точки зрения существующих теоретических взглядов (концепций, парадигм и т. п.) относительно логики построения соответствующих конструкций.

Цель статьи - проиллюстрировать на результатах теоретического анализа конструктивные особенности экономического пространства как научного феномена и показать его содержательную сторону через современные формы пространственной организации производительных сил.

По большому счету экономическое пространство представляет собой некоторую абстракцию, посредством которой специалисты пытаются раскрыть некоторые особенности восприятия реального мира и показать, как можно с ее помощью его (окружающий мир) изучать и преобразовывать. Как аргумент в пользу данного утверждения можно привести определения пространства, которые используются в других науках, например в физике, философии или логике.

Например, в физике (науке, изучающей свойства, строение, взаимодействие и формы движения материи), где наиболее часто употребляется этот термин, принято считать, что «пространство - это совокупность отношений, выражающих координацию сосуществующих объектов, - их расположение друг относительно друга и относительную величину (расстояние и ориентация)» [1, с. 227]. В философии (науке о наиболее общих законах развития природы, человеческого общества) под пространством понимается форма бытия материи, характеризующая ее протяженность, структурность, сосуществование и взаимодействие элементов во всех материальных системах [2, с. 541]. В такой науке, как логика, под пространством понимается порядок и протяженность материальных объектов и то, что оно является трехмерным [3, с. 486].

В современной регионалистике существует несколько точек зрения относительно понимания сущности экономического пространства. Так, Бияков О.А. полагает, что «...экономическое пространство - это отношение между экономическими процессами субъектов хозяйствования и совокупным экономическим процессом ( $V$-процессом) по формированию возможных результатов экономической деятельности» [4, c. 104]. В то же время Минакир П.А. считает, что «локальные экономические пространства формируются как сложные комплексы взаимодействия экономических агентов, с одной стороны, домашних хозяйств и индивидов - с другой стороны» [5, с. 25]. В диапазон данных толкований могут быть встроены и другие определения экономического пространства.

По мнению Иванова А.С., «для современных концепций (начиная примерно с середины XX века) характерно понимание экономического пространства с точки зрения действия хозяйствующих субъектов, создающих своего рода силовое поле взаимосвязей, усиливающееся и ослабевающее в результате тех или иных экономических и институциональных причин» [6, с. 157]. Батов Г.Х. полагает, что «под экономическим пространством понимается место воспроизводства системы жизнедеятельности человека, обладающей свойствами самоорганизации» [7, с. 5], а по мнению Василенко В.Н., «...экономическим пространством является (выступает) или может считаться соответствующая сложившемуся уровню развития экономических и социальных отношений форма координации (организации) и позиционирования отдельных материальных объектов или элементов производительных сил, проявляющаяся в установлении определенного порядка их вовлечения и взаимодействия в общественном производстве (по- 
Василенко В.Н. Экономическое пространство и формы пространственной организации хозяйства и населения

средством хозяйственных связей) и соблюдения закономерностей движения во времени (в любой момент и без ограничений его продолжительности)» [8, с. 76].

Как видно из приведенных определений, среди специалистов существуют различные представления о сущности экономического пространства. Связано это, скорее всего, с тем, что данное направление (в первую очередь в регионалистике, которая наиболее плотно и полно занимается решением проблем как поступательного развития элементов производительных сил, так и их перемещением на достаточно большие расстояния) в отечественной науке стало культивироваться относительно недавно и еще не наработано необходимого научного багажа знаний о природе и особенностях экономического пространства в границах локалитетов, муниципалитетов, регионов и государства в целом. В настоящее время идет активный поиск и формирование адекватных моделей экономического пространства, в которых бы отражалась объективная действительность.

Таким образом, можно констатировать, что на сегодняшний день в региональной экономике отсутствует такое определение экономического пространства, которое бы носило универсальный характер. Данное обстоятельство актуализирует поиск наиболее общих конструктивных элементов, которые бы обеспечивали универсальную формулировку определения экономическое пространство.

Представляется, что для отражения конкретного содержания экономического пространства его можно рассматривать с точки зрения семантической формы (как научный термин), организационно-экономического содержания (как научное понятие) и экономической сущности (как научная категория) процесса, которое существует и является адекватным (вполне соответствующим реальности) при решении возникающих на практике проблем или задач. Такая схема теоретического анализа определена исходя из требований системного подхода к раскрытию глубинного смысла экономического явления или процесса.

Как логическая конструкция такая схема может быть выражена в виде некоторой последовательной цепочки, состоящей из отдельных звеньев, предполагающих диалектику раскрытия любого экономического явления или процесса (в постижении его через противоречивость, цельность и развитие): семантическая форма - организационноэкономическое содержание - экономическая сущность. Данная логическая цепочка позволяет системно подойти к раскрытию природы возникновения любого экономического явления или процесса, в т. ч. может быть применима и к исследованию основных конструкций экономического пространства.

Во-первых, как научный термин экономическое пространство призвано обеспечивать смысловое содержание (наполнение) соответствующего экономического явления или процесса. С семантической точки зрения экономическое пространство представляет собой не что иное, как имя соответствующего явления или процесса, а именно представление о некоторых внешних границах, в пределах которых могут наблюдаться различные формы взаимодействия материальных объектов или элементов производительных сил. Одним из таких ограничений (границ) как раз и выступает территория, а в качестве других могут выступать, например, организационные формы взаимодействия этих объектов (элементов производительных сил) или их позиционирование по некоторым критериям.

Основной смысл, который закладывается в данный термин, предполагает упорядочивание существующего знания о возможных формах координации и порядке расположения материальных объектов или элементов производительных сил и заключается в попытке более строгого представления о некоторой реальности, которая позволяет кон- 
Василенко В.Н. Экономическое пространство и формы пространственной организации хозяйства и населения

кретизировать (уточнить и детализировать) процессы дальнейшего познания об объективной реальности.

Во-вторых, как научное понятие экономическое пространство призвано раскрыть соответствующее организационно-экономическое содержание рассматриваемого экономического явления или процесса. В данном случае назначение научного понятия состоит в формировании убедительного ответа на вопрос «что это такое?» В нашем случае понятие экономическое пространство показывает возможную внешнюю форму взаимодействия отдельных объектов или элементов производительных сил, т. е. то, что лежит на поверхности. Особенность диалектики научного знания состоит в том, что, при сохранении строгости к опытным данным, не стоит удовлетворяться только ими. Именно здесь теоретическая наука, преодолевая эмпирическую данность (основанную полностью на практическом опыте), вырабатывает концептуальное видение реальности и пытается ее объяснять при помощи понятий, выходящих за рамки полученного опыта.

Как раз понятие экономического пространства позволяет раздвинуть границы знания и дает ориентиры для дальнейших поисков, как прикладных, так и образных (мысленных). При этом критерием достоверности понятия экономическое пространство становится происхождение знания: то ли оно возникает из опыта, то ли появляется из некоторой умозрительной модели.

В-третьих, как научная категория экономическое пространство предполагает проникновение в его экономическую сущность и выяснение тех общественных отношений, которые доминируют в его структуре между соответствующими материальными объектами или элементами производительных сил. В этом случае назначение научной категории состоит в формировании аргументированного ответа на вопрос «какие отношения выражает соответствующее экономическое явление или процесс?» Относительно экономического пространства в качестве таких отношений можно предположить, с одной стороны, отношения по поводу пространственной (территориальной) организации материальных объектов или элементов производительных сил, с другой отношения по поводу формирования пространственного (территориального) взаимодействия материальных объектов или элементов производительных сил. То есть как научная категория, экономическое пространство призвано выражать отношения (или связи), возникающие между отдельными материальными объектами или элементами производительных сил посредством их возможной координации и порядка размещения на определенной территории. Именно в этом состоит сущность такого явления, как экономическое пространство.

В этой связи можно утверждать, что на сегодняшний день существует два основных постулата, в соответствии с которыми экономическое пространство воспринимается как некий феномен. С одной стороны, речь можно вести о том, что экономическое пространство представляется как некоторая форма организации и позиционирования материальных объектов или элементов производительных сил, проявляющаяся в порядке их вовлечения и взаимодействия в общественное производство и в обеспечении закономерностей движения во времени. В данном случае экономическое пространство может быть сведено к некоторому набору форм пространственной организации хозяйства и населения [8, с. 76]. С другой стороны - экономическое пространство может восприниматься как вместилище множества экономических объектов, осуществляющих хозяйственную деятельность и связанных между собой определенной совокупностью отношений. В таком случае экономическое пространство может быть сведено к пониманию его как множества экономических отношений и связей, подчиняющихся логике хозяйственной жизни [9, с. 58-59]. 
Василенко В.Н. Экономическое пространство и формы пространственной организации хозяйства и населения

В этой связи можно сделать следующее допущение: чем сложнее воспринимается и представляется (в виде соответствующей модели) экономическое пространство, тем сложнее осуществлять с ним декомпозицию (разложение на составляющие части). Доказательной базой данного утверждения в этой части могут быть представления ранее указанных авторов о возможной его форме (структуре). Так, Бияков О.А. считает, что «по форме экономическое пространство предстает как сетевая структура контрактов и соглашений, которые реализуются через экономические процессы субъектами хозяйствования. По содержанию сущность экономического пространства определяется теми функциями, которые оно выполняет» [4, с. 107], или элементами, образующими экономическое пространство: экономический процесс, экономическое время, экономическая конкуренция [4, с. 103].

В то же время Минакир П.А. пространства структуру экономического представляет «как «матрешку» взаимодействующих экономических пространств (глобального, национальных, субнациональных и локальных)» [10, с. 10]. В свою очередь А.С. Иванов, представляя форму экономического пространства «состоящего из полюсов, центров, из которых исходят центробежные силы и в которые направлены центростремительные силы, предполагает, на наш взгляд, что исследуемое региональное образование, например макрорегион, наднациональная интеграционная группировка, привлекает в свое пространство и удаляет из него множество факторов, ресурсов, создает и разрушает экономические связи и отношения» [6, с. 159].

Г.Х. Батов полагает, что «в состав этой системы (жизнедеятельности человека) входит совокупность производственных, социальных и институциональных факторов (субъектов), обеспечивающих экономическую деятельность, соблюдение норм и правил поведения субъектов хозяйствования, находящихся в определенной взаимосвязи между собой, границы взаимодействия которых могут иметь или не иметь физические очертания» [7, с. 5].

По мнению В.Н. Василенко, «в структурном отношении экономическое пространство может быть представлено в трехмерном измерении (территория, население, хозяйство), архитектоника (построение) которого позволяет упорядочивать знания об организационных формах взаимодействия материальных объектов или элементов производительных сил. При этом эти организационные формы могут приобретать любые конфигурации и размеры, например такие, как: межгосударственные экономические союзы и объединения, межрегиональные образования (экономические районы), внутрирегиональные объединения (кластеры или сети), межотраслевые структуры (вертикально или горизонтально интегрированные компании) и т. п.» [8, с. 72].

Принято считать, что в своей совокупности форма и структура экономического пространства составляют его архитектуру. Термин архитектура (лат. architectura) в настоящее время достаточно часто применяется в различных областях человеческой деятельности как в узком, так и в широком его понимании. В первом случае под архитектурой понимается искусство проектировать и строить $[11$, с. 86] и данный термин используется в строительной отрасли, зодчестве, проектировании и пр. В широком смысле слова под архитектурой принято понимать создание материально организованной среды, необходимой людям для их жизни и деятельности [12, с. 81]. И в таком виде термин применяют в политике, программировании, вычислительной технике, военном деле и др. Указанный термин используется во многих странах

Поэтому, например, в экономике [13, с. 327] «...архитектура регионального экономического пространства включает: региональную центральную ось развития, вокруг которой формируются узловые промышленные элементы, а также транспортно- 
Василенко В.Н. Экономическое пространство и формы пространственной организации хозяйства и населения

коммуникационные системы; опорный экономический каркас как сеть наиболее значительных поселений определенной территории и определяющих их транспортных коммуникаций, особая роль которого в территориальной структуре экономики заключается в том, что он и его элементы реализуют сопряженность социального и экономического развития, территориальных интегральных (районы) и специализированных (отраслевых) систем, стыков между подсистемами «производство - расселение», «производство - инфраструктура», «расселение - инфраструктура». Такой подход позволяет определить опорный экономический каркас как узловую сеть крупнейших поселений территории, в границах которой наблюдаются самая высокая концентрация экономической деятельности и самая высокая плотность населения; центры или точки роста, определяющие развитие локальных территорий и дающие начало зонам опережающего развития, они, в свою очередь, при наличии эффективной институциональной среды могут послужить площадкой для реализации кластерных инициатив; периферийные территории, имеющие инертный характер развития, но обладающие определенным потенциалом».

По мнению Василенко В.Н., «выразительными средствами архитектуры экономического пространства будут выступать: регионализация или выделение однородных и близких к ним частей пространства; формы и условия пространственной организации экономики; архитектоника или выражение закономерностей построения и развития устойчивых связей, обеспечивающих пространству целостность и тождественность (сохранение основных его свойств при внешних и внутренних изменениях); способы размещения и связанности элементов производительных сил» $[14$, с. 6$]$.

Таким образом, можно утверждать, что содержательная сторона экономического пространства или его архитектура может формироваться за счет следующих основных элементов: хозяйства, населения, экономических связей и территории. Хозяйственная составляющая будет проявляться через сложившуюся на данный момент времени структуру экономики, поселенческая - через опорный каркас расселения, экономически-связевая - через территориально-отраслевое управление хозяйственной (предпринимательской) деятельностью юридических и физических лиц, а территориальная составляющая - через установленные административные границы муниципальных образований. При этом хозяйственная составляющая и поселенческая составляющая в архитектуре экономического пространства будут проявляться через соответствующие формы пространственной организации. При восприятии экономического пространства как некоторой совокупности отношений, возникающих между субъектами хозяйствования, его архитектура может быть представлена как вместилище множества экономических объектов, осуществляющих хозяйственную деятельность и связанных между собой определенной совокупностью отношений. В этом случае экономическое пространство может пониматься как множество экономических отношений и связей, подчиняющихся логике хозяйственной жизни.

Экономическое пространство по своей сути может быть визуализировано посредством пространственной организации основных элементов производительных сил. Она включает в себя возникновение и развитие особых форм их пространственных соединений. Наиболее важными формами пространственной организации выступают формы пространственной организации хозяйства и формы пространственной организации населения. Базой для них служит локалитет - территория с расположенным на ней каким-либо одним различного рода объектом [15, с. 27]. Локалитет может быть поселенческим, промышленным, транспортным, рекреационным и т. д. (например компактный населенный пункт, предприятие, коммуникация). Сочетания локалитетов образуют конкретные формы пространственной организации населения и хозяйства. 
Василенко В.Н. Экономическое пространство и формы пространственной организации хозяйства и населения

Среди специалистов сложилось четкое понимание того, что пространственная организация хозяйства как совокупность средств производства, используемых для достижения поставленной цели, является весьма важным приоритетным направлением в пространственной экономике. Обычно хозяйство представляется в виде предприятий, организаций, транспорта и транспортных коммуникаций и т. д. И от того, насколько компактно они расположены относительно друг друга, насколько развита транспортная сеть между ними, зависит эффективность общественного производства на той или иной территории. Основными формами пространственной организации хозяйства выступают: промышленные и транспортные узлы, промышленные агломерации, кластеры и сетевые структуры и др.

В своей совокупности названные формы пространственной организации хозяйства способствуют появлению и увеличению в своих масштабах так называемых полюсов роста. Такие полюса роста собирают в себе и вокруг себя наиболее продвинутые в техническом и организационном отношении виды экономической деятельности, стимулирование развития которых способствует не только активизации экономической деятельности, но и повышению существенным образом уровня и качества жизни населения, как занятого на отдельных предприятиях, так и проживающего на окружающей их территории (за счет роста индивидуальных доходов и увеличения налоговых поступлений в местный и государственный бюджеты). Практическая ценность полюсов роста проявляется в условиях неудавшихся попыток реформирования хозяйственного комплекса. В этом случае они позволяют сохранять определенные пропорции в использовании элементов производительных сил, остающихся в наличии на данной территории. Особенно возрастает роль полюсов роста для использования свободной рабочей силы, оказавшейся невостребованной из-за резкого сокращения (ввиду неудавшейся приватизации) основных средств производства: зданий, сооружений, машин и механизмов.

Основными формами пространственной организации населения до последнего времени было принято считать опорный каркас расселения, урбанизацию, городские агломерации, сотрудничество органов местного самоуправления и др. Указанные формы пространственной организации населения (опорный каркас расселения, урбанизация и городские агломерации) представляют собой несущую часть экономического пространства, которые сами по себе не могут оказывать решающего воздействия на характер этого развития и появление новых точек развития на соответствующей территории. Движущей силой в этих условиях становятся современные формы сотрудничества органов местного самоуправления и общественных организаций непосредственно самого населения.

Формы пространственной организации населения сопровождают появление и разрастание так называемых точек развития: сопряжено это с тем, что особенностью современного этапа пространственного развития является уменьшение количества сельских населенных пунктов (ежегодно с карты области исчезает несколько сел или деревень) и перемещение сельских (деревенских) жителей в города и поселки городского типа. Многие населенные пункты под воздействием сокращения численности проживающего населения теряют свой статус. В этих условиях появляется необходимость поиска более действенных форм обеспечения жизнедеятельности населения, чтобы преодолеть негативные последствия демографического кризиса.

Таким образом, полученные результаты теоретического анализа экономического пространства как научного феномена позволяют сделать ряд следующих обобщений:

1) до настоящего момента в научном сообществе еще не сложилась единая позиция относительно экономического пространства как понятия и как научной категории. 
Василенко В.Н. Экономическое пространство и формы пространственной организации хозяйства и населения

Используемые в научном обиходе определения экономического пространства охватывают весьма широкий спектр его характеристик, что вносит определенную сумятицу не только в реальное восприятие окружающего мира, но и в виртуальное его представление. Доминирование широких абстракций в толковании понятия экономического пространства представителями научного сообщества не способствует его формализации, а соответственно и применению в практической деятельности органов государственной власти, местных органов самоуправления и субъектов хозяйствования из-за разногласий в его содержательном наполнении;

2) сложившийся диапазон понимания и толкования экономического пространства не позволяет пока унифицировать его форму и структуру, что осложняет научный поиск его архитектуры и архитектоники. В связи с этим возникают прикладные и методические проблемы в эффективном (экономном и результативном) применении научного инструментария стратегического, оперативного и текущего управления экономическими процессами и явлениями на муниципальном, региональном и государственном уровнях. Во многом это происходит из-за неоднозначности восприятия его основных свойств;

3) существует необходимость в унификации и стандартизации многих положений, которые могли бы пополнить теоретическую основу такой научной дисциплины, как пространственная экономика. Без такой работы многие начинания отечественных ученых и практиков, которые плотно занимаются решением соответствующих вопросов на муниципальном, региональном, субрегиональном и государственном уровнях, будут носить разобщенный и фрагментарный характер и не будут способствовать дальнейшему развитию научной мысли в данной области научных знаний.

\section{Литература}

1. Физический энциклопедический словарь: в 5 т. - Т. 4. - М.: Советская энциклопедия, 1965. - 592 с.

2. Философский энциклопедический словарь / гл. редакция: Л.Ф. Ильичев, П.Н. Федосеев, С.М. Ковалев, В.Г. Панов. - М.: Советская энциклопедия, 1983. - 840 с.

3. Кондаков Н.И. Логический словарь-справочник. - 2-е изд. - М.: Наука, 1975. $720 \mathrm{c}$.

4. Бияков O.A. Экономическое пространство: сущность, функции, свойства // Вестник Кузбасского государственного технического университета. - 2004. - № 2. C. 101-108.

5. Минакир П.А. Экономический анализ и измерения в пространстве // Пространственная экономика. - 2014. - № 1. - С. 12-39.

6. Иванов А.С. Экономическое пространство макрорегиона: методологические аспекты внешнеэкономической деятельности // Известия ВолгГТУ. - 2012. - № 16 (103). - C. 157-161.

7. Батов Г.Х. Экономическое пространство: проблемы становления в регионе // Региональная экономика: теория и практика. - 2014. - № 42 (369). - С. 2-11.

8. Василенко В.Н. Многомерность параметров региона: территории, системы, пространства: монография / науч. ред. В.В. Дружинина. - Дружковка: Юго-Восток, 2016. $408 \mathrm{c}$.

9. Иванов А.С. Развитие регионального экономического пространства как сегмента пространства глобальной экономики // Вестник ВолГУ. Сер. 3: Экономика. Экология. -2010 . - № 2. - С. 58-63. 
Василенко В.Н. Экономическое пространство и формы пространственной организации хозяйства и населения

10. Минакир А.П. Национальная стратегия пространственного развития: добросовестные заблуждения или намеренные упрощения? // Пространственная экономика. 2016. - № 3. - С. 7-15.

11. Новейший словарь иностранных слов и выражений. - Минск: Современный литератор, 2003. - 976 с.

12. Советский энциклопедический словарь / гл. ред. А.М. Прохоров; редкол.: Гусев А.А. и др. - 4-е изд. - М.: Сов. энциклопедия, 1987. - 1600 с.

13. Гатауллин Р.Ф., Каримов А.Г., Аслаева С.Ш. Механизм формирования архитектуры регионального экономического пространства // Фундаментальные исследования. - 2016. - № 7. - С. 324-329.

14. Василенко B.Н. Архитектура регионального экономического пространства: монография; НАН Украины. Ин-т экономико-правовых исследований. - Донецк: ООО «Юго-Восток, Лтд», 2006. - 311 с.

15. Гранберг А.Г. Основы региональной экономики: учебник для вузов. - 2-е изд. - М.: ГУ ВШЭ, 2001. - 495 с.

Поступила в редакциию 5 июля 2017 г.

UDC 332.1: 334.78

DOI: $10.21779 / 2500-1930-2017-32-3-55-63$

\section{Economic space and forms of spatial organization of economy and population}

\section{V.N. Vasilenko}

State Institution «Institute of Economic Research»; DNR, 283048, Donetsk, University st., 77; bulava1953@mail.ru

Solutions of contemporary problems of regional development are often associated with the search for new tools that can provide adequate perception and impact on the surrounding reality. One of these tools is the spatial approach. Such approach allows to consider any economic object in its spatio-linkage construction. In this regard, the economic space proposed to consider through the prism, first, some forms of spatial organization and positioning of material objects or elements of productive forces, and secondly, a variety of economic relations and ties. Because of the absence of a universal definition of economic space, the article proposes a logical scheme of its cognition from the point of view of the semantic form (scientific term), organizational-economic content (scientific concept) and economic essence (scientific category). Based on the views of some Russian regionalist scholars, the distinctive features of the construction (form and content) of the economic space are shown. The architecture (content side) of the economic space is shown as a combination of the following elements: economy, population, economic ties and territory.

Keywords: spatial approach, productive forces, forms of spatial organization of economy and population, architecture of economic space.

Received 5 July, 2017 